\title{
On Geometrical Characteristics of WC-Co Round Cavities After ED-Machining with Different Grades of CuW Electrodes
}

\author{
Giovani Conrado Carlini ${ }^{a}$, Cassiano Rodrigues Moura ${ }^{b}$, Fred Lacerda Amorim ${ }^{a^{*}}$ (1),
}

Walter Lindolfo Weingaertner ${ }^{c}$

\begin{abstract}
${ }^{a}$ Pontifícia Universidade Católica do Paraná (PUCPR), Programa de Pós-Graduação em Engenharia Mecânica - PPGEM, Imaculada Conceição, 1155, Prado Velho, 80215 901, Curitiba, PR, Brasil ${ }^{b}$ Instituto Federal de Santa Catarina (IFSC), Rua dos Imigrantes, 445, 89254 430, Jaraguá do Sul, SC, Brasil ${ }^{c}$ Universidade Federal de Santa Catarina (UFSC), Departamento de Engenharia Mecânica (EMC), Campus Universitário Trindade, 88010 970, Florianópolis, SC, Brasil
\end{abstract}

Received: January 29, 2020; Revised: April 13, 2020; Accepted: April 20, 2020

\begin{abstract}
Cemented carbides (WC-Co) are difficult to be processed by conventional machining processes. Electrical discharge machining (EDM) appears as an efficient technology to manufacture WC-Co products with high accuracy. In EDM literature no research works investigating the influences of different grades of $\mathrm{CuW}$ electrodes on geometrical characteristics when ED-machining the same cemented carbide was found. This work presents an investigation on ED-Machining of cemented carbide (WC-Co) with 10\% Co using two grades of coper-tungsten $(\mathrm{CuW}$ ) electrodes with $65 \%$ and $85 \%$ of tungsten. ED-Machining experiments were carried out under rough, semifinish and finish regimes with input variables discharge current $i_{e}$, discharge duration $t_{e}$ and pulse interval time $t_{o}$ using analysis of variance (ANOVA) based on design of experiments with complete factorial $3^{2}$. Output variables evaluated were WC-Co workpiece geometrical characteristics 3D surface roughness and round cavities circularity measures. Results showed that ED-Machining regime is the most significant parameter on both WC-Co workpiece circularity and surface roughness measures. Electrodes grades $\mathrm{CuW} 65$ and CuW85 presented similar results on workpiece circularity and 3D surface roughness.
\end{abstract}

Keywords: ED-Machining; $C u W$ eletrodes; WC-Co workpiece; Geometrical Characteristics.

\section{Introduction}

Electrical discharge machining (EDM) is recognized as one of the most non-conventional machining processes widely used in industry, owing to its possibility of producing complex shapes with high accuracy in any electrical conductive material, regardless its mechanical properties ${ }^{1}$. In ED-Machining, there is no direct contact between workpiece and electrode; discrete electrical discharges are produced between them in a liquid dielectric medium. ED-Machining high temperatures of about $20,000{ }^{\circ} \mathrm{C}$, during the spark occurrence, are responsible to melt and vaporize small amounts of material of both workpiece and electrode, with no mechanical stresses taking place $\mathrm{e}^{2,3}$.

Precision metal-mechanical industry commonly deals with hard-to-machine materials such as cemented carbides (WC-Co), which are difficult to be processed by conventional machining processes. As for that, such materials are better machined by non-conventional manufacturing processes such as ED-Machining, once its material removal principle works through thermal input into the material, which inherently is independent of material mechanical strength ${ }^{4}$.

WC-Co composite material is composed by Cobalt as binder and WC that is a non-oxide ceramic, where hexagonal closely packed layers of W atoms are separated by closely

*e-mail: fred.amorim@pucpr.br. packed layers of $\mathrm{C}$ filling one-half of the interstices, giving rise to a six-fold trigonal prismatic coordination for the atomic structures ${ }^{5}$. Effective sinking EDM electrode materials for removal of WC-Co are copper-tungsten alloys $(\mathrm{CuW})$, since their thermo-physical properties such as melting point, electrical and thermal conductivities, thermal resistivity are better than those presented on common EDM electrode materials, like graphite and copper ${ }^{4}$.

Discharge energy $\left(\mathrm{W}_{\mathrm{e}} \approx \mathrm{u}_{\mathrm{e}} \cdot \mathrm{i}_{\mathrm{e}} \cdot \mathrm{t}_{\mathrm{e}}[\mathrm{mJ}]\right.$, where $\mathrm{u}_{\mathrm{e}}$ is the discharge voltage, $\mathrm{i}_{\mathrm{e}}$ is the discharge current, $\mathrm{t}_{\mathrm{e}}$ is the discharge durantion) used in working gap is the main ED-machining factor responsible to process performance in terms of material removal rate $\mathrm{V}_{\mathrm{w}}\left[\mathrm{mm}^{3} / \mathrm{min}\right]$, volumetric relative wear $\vartheta\left(\vartheta=\right.$ electrode wear rate $\left[\mathrm{mm}^{3} / \mathrm{min}\right] /$ material removal rate $\left.\left[\mathrm{mm}^{3} / \mathrm{min}\right]\right)$, workpiece surface integrity and cavity geometrical characteristics ${ }^{6}$. Duszová et al. ${ }^{7}$ evaluated EDM parameters conditions for machining WC-Co using $\mathrm{CuW}(70 \% \mathrm{~W}$ and $30 \% \mathrm{Cu}$ ) electrodes in different ED-machining regimes, searching for improved data for volumetric relative wear $\vartheta$, material removal rate $\mathrm{V}_{\mathrm{w}}$ and surface roughness $\mathrm{R}_{\mathrm{a}}$. They concluded that variation of the duty factor $\left(\tau=t_{i} / t_{i}+t_{o}[\%]\right.$, where $t_{i}$ is the pulse time and $t_{0}$ is the pulse interval time ) slightly improves material removal rate $\mathrm{V}_{\mathrm{w}}$ and that open circuit voltage $\hat{u}_{i}$ increases $\mathrm{V}_{w}$ and decreases $\mathrm{R}_{\mathrm{a}}$ values. In a study by Qu et al. ${ }^{8}$ when ED-machining WC-Co workpiece 
using $\mathrm{CuW}$ with high energy density, it was observed a reduction of hardness in the region near the workpiece surface. Carlini et al. ${ }^{9}$ investigated the ED-Machining of WC-Co with $\mathrm{CuW}$ electrodes using very high discharge energy and observed an increase of both surface roughness and heat-affected zone thickness.

Senthilkumar et al. ${ }^{10}$ report that in precision metal-mechanical industries one important goal is to manufacture components with reasonable costs and according to their predefined requirements for precise dimensions and high geometrical accuracy. In this sense, geometrical tolerances such as circularity, cylindricity, perpendicularity and radial overcut must be constantly improved. They verified that circularity, surface roughness and workpiece overcut increase with the use of high discharge currents $i_{e}$, as well as the number of microvoids and craters sizes.

Data pertaining to circularity, cylindricity and perpendicularity of round cavities are scarce in EDM literature ${ }^{11}$. Circularity is defined as a condition of a surface of revolution (sphere, cone, and cylinder) where all points of the surface intersected by any plane perpendicular to a common axis (cone, cylinder) or passing through a common center (sphere) are equidistant from the axis of the center ${ }^{12}$. This indicates that circularity can be altered in two ways: by changes in area and by changes in the perimeter of a particle. To consider this, an ideal perfect circle (true circle) is assumed. If the area and perimeter do not change, then circularity is constant. Consequently, it should be possible to determine roundness if circularity can be corrected using aspect ratio. In other words, if it is possible to combine the difference in circularity value due to aspect ratio with the circularity itself, then the aspect ratio-corrected circularity can be used to represent roundness ${ }^{13}$. Adamczak et al. ${ }^{14}$ presented the principle of reference method and the importance of cylindricity measurement and also the method for comparing the cylindrical profile.

Selvarajan et al. ${ }^{12}$ optimized ED-Machining parameters for enhancing circularity, cylindricity and perpendicularity of Si 3N4-TiN Composite holes by employing grey relational analysis technique. Dhanabalan et al. ${ }^{15}$ analyzed ED-Machining process on form tolerances of inconel 718 and 625. Results showed that increasing discharge duration $\mathrm{t}$, the circularity, cylindricity and perpendicularity values decreased up to discharge duration $t_{e}=350 \mu \mathrm{s}$, and when applying higher $t_{e}$ their values increased.

Recently, Popli and Gupta ${ }^{16}$ Investigated the circularity and conicity of a super alloy during rotary ultrasonic machining with the variation on tool rotation, feed rate, ultrasonic power abrasive, mesh size and variable electrode design. They observed that variation in abrasive size and tool shapes has significant effect on the performance of machining.

Tiwary et al. ${ }^{17}$ studied the effect of dielectrics on circularity during micro-electro-discharge machining of Ti-6Al-4V using hydrocarbon oil, pure deionized water and deionized water mixed with $\mathrm{Cu}$ powder. They concluded that hydrocarbon oil obtained the lowest circularity in all discharge currents $i_{e}$ used, with the best result for current $i_{e}=2$ A. D'Urso and Merla $^{18}$ investigated the influence of electrode materials on geometrical characteristics of micro-EDM holes in terms of conicity and diametral overcut. Copper, brass and tungsten carbide (WC-Co) electrodes were used for three different discharge energies. From $0.05 \mathrm{~mm}$ to $0.09 \mathrm{~mm}$ diametrical overcuts were produced and the best result was achieved for cooper electrode at low discharge current $i_{e}$.

Physical and electrical characteristics of ED-Machining debris were studied by Murray et al. ${ }^{19}$ and it was verified debris with particle sizes as small as $1 \mathrm{~nm}$ and as large as $10 \mu \mathrm{m}$. They concluded that debris particles were present in all regions around workpiece samples, adding evidence that debris plays a key role in electrical conditions in working gap, and also that debris sizes showed no clear dependence on discharge current $i_{\mathrm{e}}$. However, they did not investigate geometrical aspects such as workpiece overcut and form error.

Muttamara et al. ${ }^{20}$ studied the effects of graphite and copper electrodes, under the same ED-Machining parameter settings, over the WC-Co workpiece surface characteristics. It was observed that surface roughness produced with graphite electrode was higher than that of copper electrode. According to them, it is probably due to the graphite particles from graphite electrode that produces pores on the workpiece surface layer, which does not occur when ED-machining with copper electrodes. Shabgard et al. ${ }^{21}$ and Kunieda et al. ${ }^{22}$ reported on the influence of ED-Machining on surface integrity of WC-Co workpiece. They found that the surface roughness achieved through ultrasonic assisted EDM is marginally higher than the roughness achieved by conventional EDM process. Also, in sinking EDM hydrocarbon dielectrics are normally used because surface roughness is better and tool electrode wear is lower when compared to deionized water as dielectric fluid.

Research works were found regarding ED-Machining performance applied to different grades of WC-Co on aspects related to technological performance measures, workpiece morphology and surface integrity, when using one single grade of $\mathrm{CuW}$ electrode $23-25$. However, so far in EDM literature no research works investigating the influences of different grades of $\mathrm{CuW}$ electrodes on surface roughness and circularity when ED-machining the same cemented carbide was found.

In this regard, the objective of present work is to evaluate the effects of two different grades of copper-tungsten electrodes (CuW85\% and $\mathrm{CuW65 \% )}$ when ED-machining cemented carbide (WC-Co10\%) concerning workpiece 3D surface roughness $(\mathrm{Sa})$ and circularity for three levels of discharge energy $\left(\mathrm{W}_{\mathrm{e}} \approx \mathrm{u}_{\mathrm{e}} \cdot \mathrm{i}_{\mathrm{e}} \cdot \mathrm{t}_{\mathrm{e}}[\mathrm{mJ}]\right)$.

\section{Experimental Procedures}

The experiments were conducted with three different input levels of discharge energy $\left(\mathrm{W}_{\mathrm{e}} \approx \mathrm{u}_{\mathrm{e}} \cdot \mathrm{i}_{\mathrm{e}} \cdot \mathrm{t}_{\mathrm{e}}[\mathrm{mJ}]\right)$ for rough, semi-finish and finish regimes (Table 1) and three fold replicated for each regime. As output performance variables the WC-Co workpiece circularity and surface roughness $\mathrm{Sa}$ (average height of selected area) were evaluated. A negative polarity was used to the electrode (cathode) and the WC-Co workpiece as the anode, due to the high percentage of WC ceramic phase in the WC-Co alloy, which would inhibit the emission of primary electrons that are responsible to start the ionization process and to accelerate the dielectric voltage breakdown, and then faster create the plasma channel ${ }^{6}$. The values of duty factor $\tau\left(\mathrm{t}_{\mathrm{i}} / \mathrm{t}_{\mathrm{i}}+\mathrm{t}_{\mathrm{o}}\right)$ was progressively 
reduced from the rough to finish regime (0.64 to 0.11 ), providing adequate flushing condition of debris away from the working gap, by setting a longer value for interval time $t_{0}$.

An EDM machine-tool +GF+ AgieCharmilles ${ }^{\circ} \mathrm{CNC}$, model SP1, was used to carry out the experiments. A hydrocarbon dielectric fluid with $3.12 \mathrm{cSt}$ viscosity at $40^{\circ} \mathrm{C}$, flash point of $134^{\circ} \mathrm{C}$ and $0.01 \mathrm{wt} \%$ of aromatic contents was used and $0.1 \mathrm{MPa}$ pressure flushing was provided by applying $6.35 \mathrm{~mm}$ diameter rigid hoses positioned at $180^{\circ}$ of each other and placed near the workpieces. $10 \mathrm{~mm}$ diameter cylindrical bars of two grades of $\mathrm{CuW}$ electrodes ( $\mathrm{CuW} 65 \%$ and $\mathrm{CuW} 85 \%$ ) were mounted axially in line with round submicron grain size WC-Co workpiece samples with chemical composition shown in Table 2 . The chemical composition analysis was performed by a scanning electron microscope (SEM) of Tescan ${ }^{\circledR}$ manufacturer; model VEGA3 LMU, equipped with an energy dispersive spectroscopy (EDS) probe manufactured by Oxford Instruments. An especial assembly device was designed and manufactured, providing adequate clamping of the WC-Co samples, as shown in Figure 1.

As shown in Figure 2, WC-Co workpieces circularity measurements were carried out in a Mitutoyo ${ }^{\circledR}$ roundness equipment, model RA 1600. A preset filter cut off at 50 ripples per revolution (UPR), as recommended in the instruction manual observing the dimensional fields of the samples, was used. All measurements were performed with a $1 \mathrm{~mm}$ diameter ruby probe. For the computational interface, the Roundpak $^{\circledR}$ software was applied, which allows the plotting of graphs for enhanced understanding the measurements.
Topographical analysis of the WC-Co workpiece surfaces were made with an optical stereoscopic microscope Discovery V12, Carl Zeiss ${ }^{\circledR}$. The workpiece surface morphology was taken by a Leica ${ }^{\circledR}$ DCM 3D digital microscope with dimensions area of $1.27 \times 0.95 \mathrm{~mm}^{2}$. Confocal Z scan $200 \mu \mathrm{m}$ with lateral resolution of $0.1 \mu \mathrm{m}$ and vertical resolution of $2.0 \mu \mathrm{m}$ was used, totalizing $384 \times 288$ data points. Workpiece surface roughness was measured using Leica Scan topography in accordance with I SO 4287: 2002 and ISO 25178-2: 2012. 3D roughness measurement differs from two-dimensional measurement by assessing roughness in a given volume, providing distribution and regularity data in the third dimension. Surface roughness Sa (average height of selected area) was used for the characterization of each sample topography after ED-machining for the three tested regimes. Only the WC-Co cavity bottom was used for 3D superficial roughness measurement.

\section{Results and Discussions}

For enhanced understanding of the graphics, Figure 3 presents the WC-Co workpiece circularity variation results for ED-Machining under rough $\left(i_{\mathrm{e}}=37 \mathrm{~A}, \mathrm{t}_{\mathrm{e}}=180 \mu \mathrm{s}\right)$, semi-finish $\left(i_{e}=11 \mathrm{~A}, t_{e}=56 \mu \mathrm{s}\right)$ and finish regimes $\left(\mathrm{i}_{\mathrm{e}}=4 \mathrm{~A}, \mathrm{t}_{\mathrm{e}}=13 \mu \mathrm{s}\right)$, using the two $\mathrm{CuW}$ electrodes grades (CuW65\% and CuW85\%). It can be seen that from finish to rough regimes, independently of $\mathrm{CuW}$ electrode grade, the circularity variation increases substantially.

It is probably explained by the increase of discharge energy $\left(\mathrm{W}_{\mathrm{e}}=\mathrm{u}_{\mathrm{e}} \cdot \mathrm{i}_{\mathrm{e}} \cdot \mathrm{t}_{\mathrm{e}}[\mathrm{mJ}]\right)$, from finish to rough machining,

Table 1. Electrical input parameters of energy for ED-Machining experiments.

\begin{tabular}{ccccccc}
\hline \multirow{2}{*}{ Regime } & $\begin{array}{c}\text { Electrode } \\
\text { Polarity }\end{array}$ & $\mathrm{u}_{\mathrm{i}}[\mathrm{V}]$ & $\mathrm{t}_{\mathrm{e}}[\mu \mathrm{s}]$ & $\mathrm{t}_{\mathrm{o}}[\mu \mathrm{s}]$ & $\mathrm{i}_{\mathrm{e}}[\mathrm{A}]$ & \multicolumn{1}{c}{${ }[\%]$} \\
\hline Rough & negative & 80 & 180 & 100 & 37.0 & 0.64 \\
\hline Semi-finish & negative & 80 & 56 & 24 & 11.0 & 0.70 \\
\hline Finish & negative & 80 & 13 & 100 & 4.0 & 0.11 \\
\hline
\end{tabular}

Table 2. Chemical composition of cemented carbide and electrodes.

\begin{tabular}{cccccc}
\hline \multirow{2}{*}{ Materials } & \multicolumn{5}{c}{ Element - Chemical composition [\%] } \\
\cline { 2 - 6 } & $\mathrm{W}$ & $\mathrm{C}$ & $\mathrm{Co}$ & $\mathrm{Cu}$ & Others \\
\hline Samples WC-Co & 80,57 & 8,57 & 10,43 & - & 0,43 \\
\hline Electrode CuW65 & 65,00 & - & - & 35,00 & $\mathrm{n} / \mathrm{D}$ \\
\hline Electrode CuW85 & 85,00 & - & - & 15,00 & $\mathrm{n} / \mathrm{D}$ \\
\hline
\end{tabular}
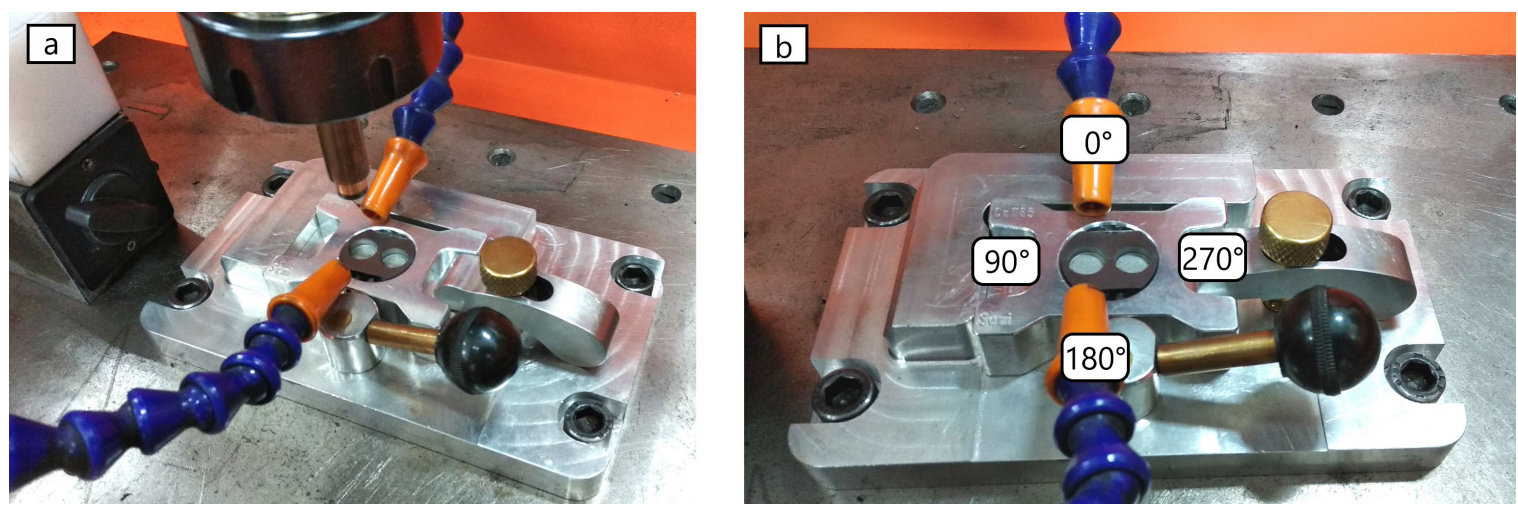

Figure 1. (a) Assembly device for samples and electrodes clamping and (b) positions for circularity measurements. 

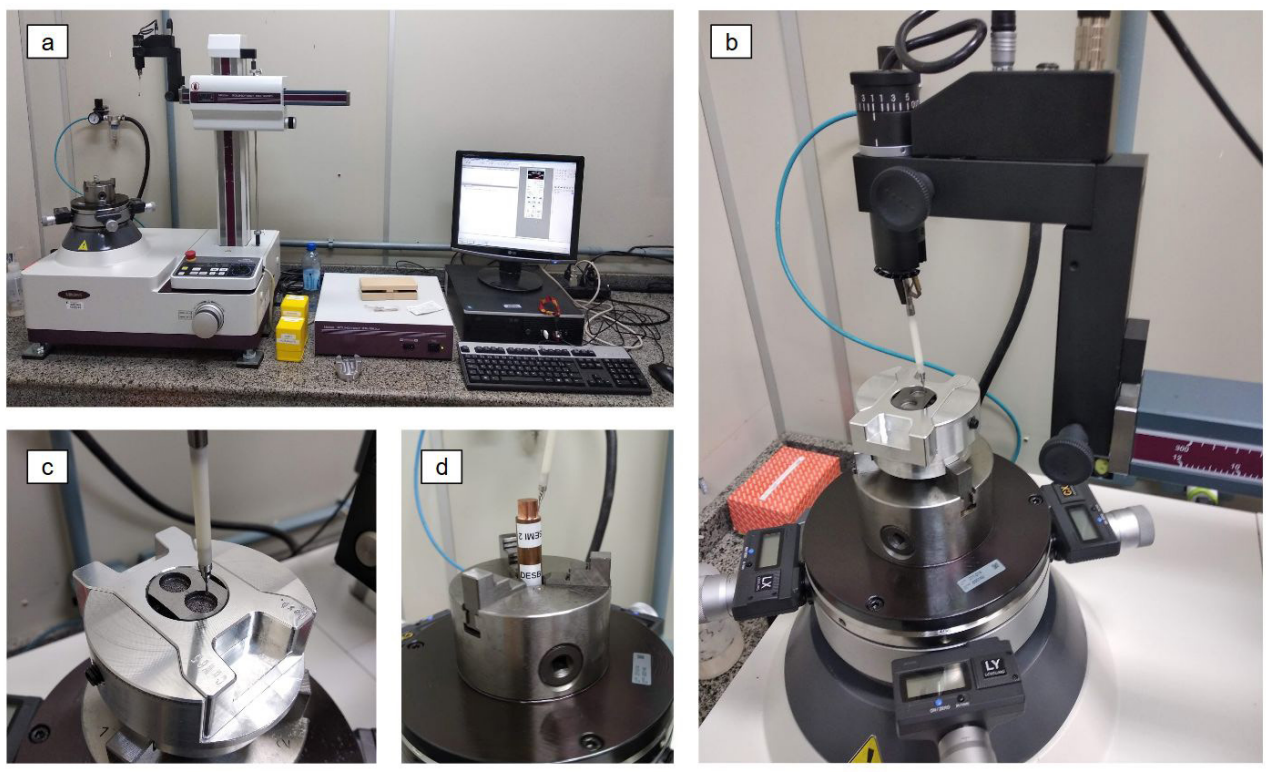

Figure 2. (a) Roundness equipment overview, (b) workpiece clamping detail, (c) workpiece measurement and (d) electrode measurement.

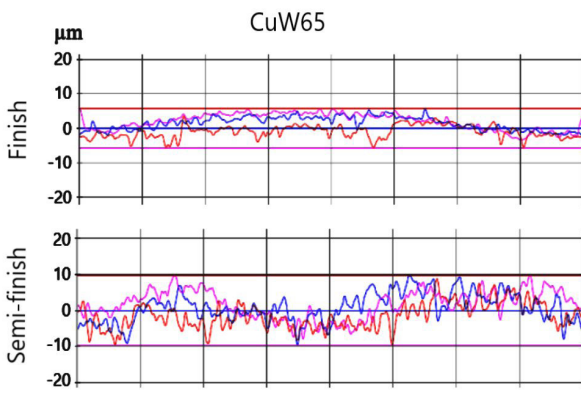

CuW85
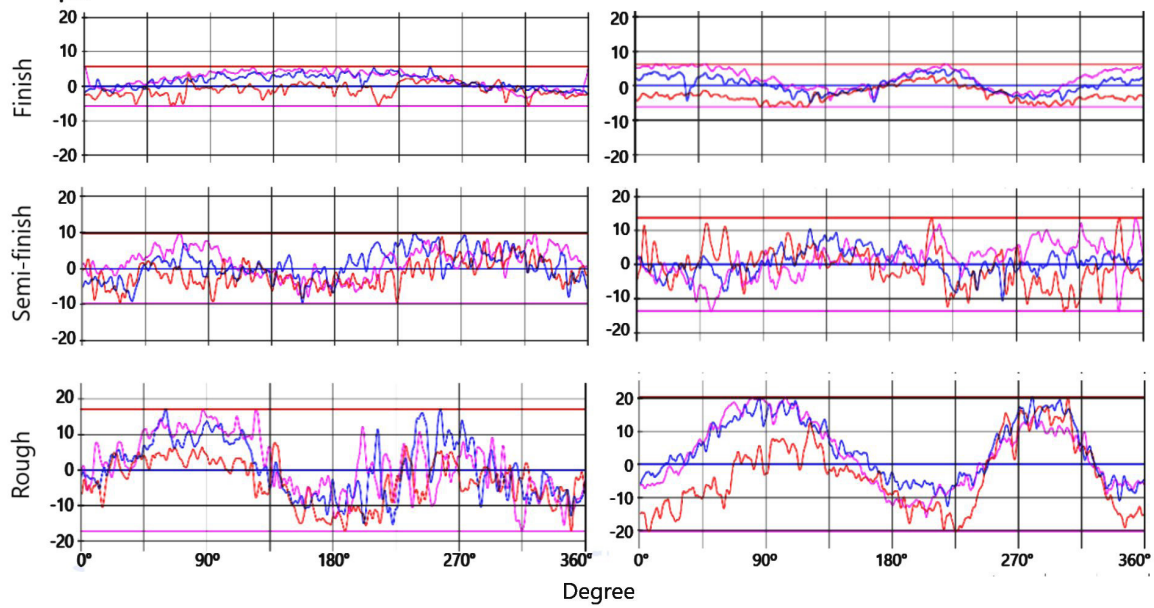

Figure 3. Circularity deviations for rough, semifinish and finish ED-Machining with both CuW electrode grades.

that provides both higher plasma channel pressure and higher temperature over the melted eletrode/workpiece pools. Thus, when the higher energy plasma channel is interrupted, by setting the interval time $t_{0}$, more material is violently expelled away from the melted pools of the electrode/workpiece for rough regime. As consequence, more amount of debris concentrates in a non-uniform way in the working gap. It then provides the increase in circularity deviation, due to the occurance of more sparks where the debris concentration are higher, exactly because in such places the dielectric breakdown easier occurs.

The circularity geometry shape for WC-Co workpiece, under ED-Machining with rough regime $\left(\mathrm{i}_{\mathrm{e}}=37 \mathrm{~A}, \mathrm{t}_{\mathrm{e}}=180 \mu \mathrm{s}\right)$, can be also observed three-dimensionally in Figure 4. The depth of erosion was $3.5 \mathrm{~mm}$; however, the measuring probe reached $2.0 \mathrm{~mm}$ due to its mechanical construction.
It is possible to observe that at the input positions of clean dielectric fluid the circularity error is smaller than at the output places of the contaminated dielectric. It corroborates the previous explanation, i.e. where debris presence is higher more material is removed from the workpiece, causing an increase in circularity deviation.

Figure 5 shows a comparison of WC-Co workpiece circularity distribution for the rough, semi-finish and finish regimes with $\mathrm{CuW} 65$ and $\mathrm{CuW} 85$ electrodes. It is possible to observe the existence of circularity deviations within the same regime. Such deviations are more prominent for the roughing and semi-finishing regimes. These deviations within the same regime, for semi-finish $\left(\mathrm{i}_{\mathrm{e}}=11 \mathrm{~A}, \mathrm{t}_{\mathrm{e}}=56 \mu \mathrm{s}\right)$ and rough $\left(\mathrm{i}_{\mathrm{e}}=37 \mathrm{~A}, \mathrm{t}_{\mathrm{e}}=180 \mu \mathrm{s}\right)$ regimes, are related to the higher surface roughness obtained as the discharge energy $\left(\mathrm{W}_{\mathrm{e}} \approx \mathrm{u}_{\mathrm{e}} \cdot \mathrm{i}_{\mathrm{e}} \cdot \mathrm{t}_{\mathrm{e}}[\mathrm{mJ}]\right)$ applied is increased. In these regimes, with higher values 
of $\mathrm{W}_{\mathrm{e}}$, the dielectric fluid is more contaminated with EDM byproducts and flows in the working gap in a turbulent way. This fact then provides non-uniform material removal around the cavity, causing such circularity deviation. On the other hand, in finish regime $\left(i_{e}=4 \mathrm{~A}, \mathrm{t}_{\mathrm{e}}=13 \mu \mathrm{s}\right)$, where low discharge current is used, less material is removed from the workpiece. So, lower surface roughness is achieved along with both a more uniform flow and less contaminated dielectric fluid. This fact is responsible for the lower circularity deviation in this ED-machining regime. The aforesaid performance occurred in the same way for both electrode grades (CuW65 and CuW85), as presented in Table 3 .

Table 4 presents an ANOVA for WC-Co workpiece circularity when ED-Machining under rough, semifinish and finish ED-Machining with $\mathrm{CuW65 \%}$ and $\mathrm{CuW} 85 \%$ electrodes, in order to identify the most significant parameters. The input data selection was defined in ED-Machining system variables: $\mathrm{CuW}$ electrodes grades, general error of electrodes circularity and selected ED-Machining regimes. The ANOVA results show an error of $8.4 \%$, which means that the relational analysis results have an accuracy of $91.6 \%$ in significant level of $95 \%$. From the ANOVA table, it is evidently seen that ED-Machining regimes (88.99\%) plays a major role in determining the WC-Co workpiece circularity. The influence of the two $\mathrm{CuW}$ electrode grades on WC-Co circularity was not significant.

In order to validate the ANOVA results a standardized residual analysis was carried out to verify that there is no distribution of occurrences with respect to the reference line in Figure 6a. A second test, shown in Figure 6b, was done to check if there is a trend among the factors. It is observed that the greater the dispersion the lower the trend on the variables. So, it means that the ANOVA treatment can be considered as valid.

Figure 7 shows the 3D topography and WC-Co workpiece surface roughness results for ED-machining under rough

Table 3. WC-Co workpiece circularity deviations for rough, semifinish and finish ED-Machining using $\mathrm{CuW} 65 \%$ and $\mathrm{CuW} 85 \%$ electrodes.

\begin{tabular}{lcc}
\hline \multirow{2}{*}{ Regime } & \multicolumn{2}{c}{ Average Circularity $[\mu \mathrm{m}]$} \\
\cline { 2 - 3 } & \multicolumn{1}{c}{ CuW65 } & CuW85 \\
\hline Rough & $39.712 \pm 5.829$ & $41.430 \pm 6.174$ \\
\hline Semi-finish & $26.858 \pm 5.527$ & $27.572 \pm 5.557$ \\
\hline Finish & $12.193 \pm 2.383$ & $12.599 \pm 2.340$ \\
\hline
\end{tabular}

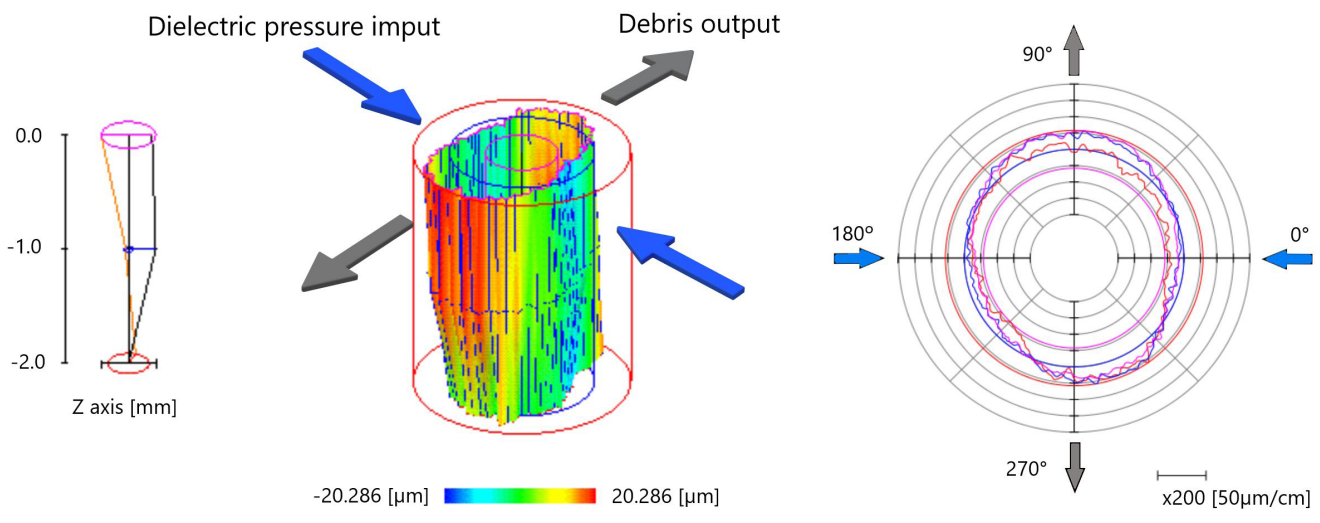

Figure 4. 3D circularity representation for rough EDM regime $\left(\mathrm{i}_{\mathrm{e}}=37 \mathrm{~A}, \mathrm{t}_{\mathrm{e}}=180 \mu \mathrm{s}\right)$.
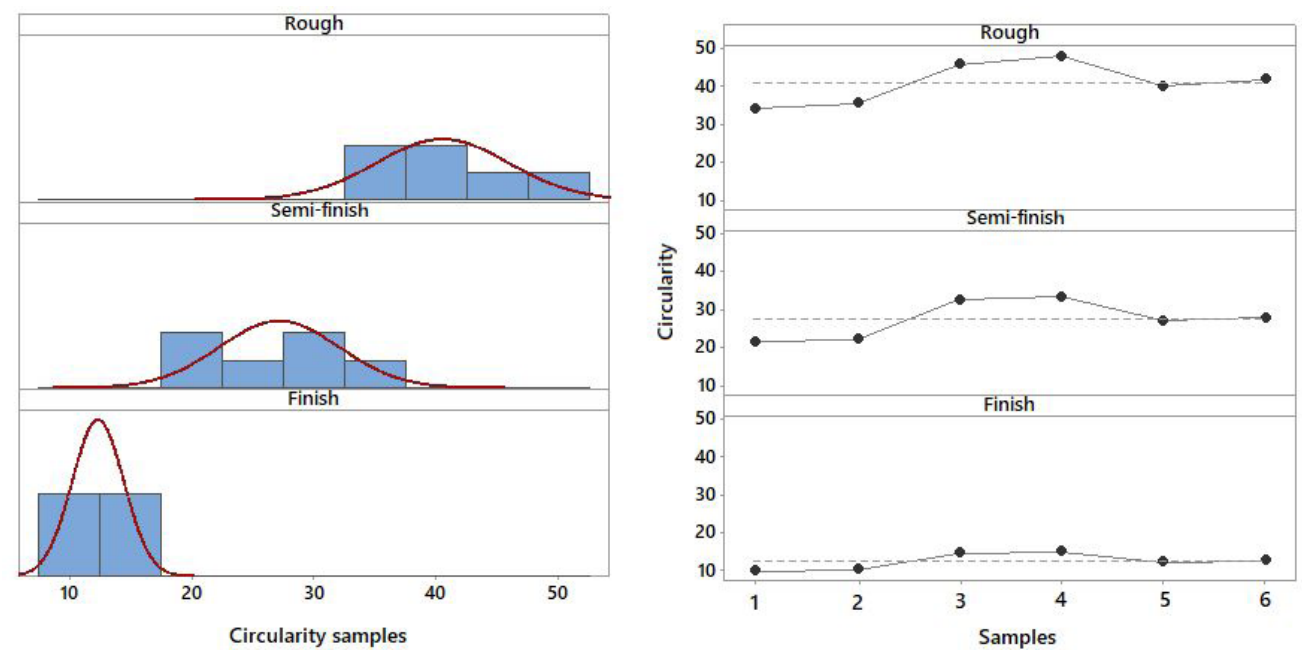

Figure 5. Distribution of circularity $[\mu \mathrm{m}]$ for rough $\left(i_{e}=37 \mathrm{~A}, t_{e}=180 \mu \mathrm{s}\right)$, semi-finish $\left(i_{e}=11 \mathrm{~A}, \mathrm{t}_{\mathrm{e}}=56 \mu \mathrm{s}\right)$ and finish regimes $\left(\mathrm{i}_{\mathrm{e}}=4 \mathrm{~A}, \mathrm{t}_{\mathrm{e}}=13 \mu \mathrm{s}\right)$. 
Table 4. ANOVA table for ED-Machining effects on WC-Co circularity.

\begin{tabular}{crrrrrrr}
\hline Source & DF & Seq SS & Contribution & Adj SS & Adj MS & F-Value & P-Value \\
\hline Model & 13 & 4907,04 & $91,60 \%$ & 4907,04 & 377,46 & 18,46 & 0,000 \\
\hline Blocks & 2 & 128,90 & $2,41 \%$ & 128,90 & 64,45 & 3,15 & 0,063 \\
\hline Linear & 4 & 4775,32 & $89,14 \%$ & 4775,32 & 1193,83 & 58,39 & 0,000 \\
\hline CuW Eletrode Alloy & 1 & 0,00 & $0,00 \%$ & 0,00 & 0,00 & 0,00 & 1,000 \\
\hline Electrode Error & 1 & 8,05 & $0,15 \%$ & 8,05 & 8,05 & 0,39 & 0,537 \\
\hline EDM Regime & $\mathbf{2}$ & $\mathbf{4 7 6 7 , 2 6}$ & $\mathbf{8 8 , 9 9 \%}$ & $\mathbf{4 7 6 7 , 2 6}$ & $\mathbf{2 3 8 3 , 6 3}$ & $\mathbf{1 1 6 , 5 8}$ & $\mathbf{0 , 0 0 0}$ \\
\hline 2-Way Interactions & 5 & 2,82 & $0,05 \%$ & 2,82 & 0,56 & 0,03 & 1,000 \\
\hline Alloy*Electrode Error & 1 & 0,00 & $0,00 \%$ & 0,00 & 0,00 & 0,00 & 1,000 \\
\hline Alloy*Regime & 2 & 0,00 & $0,00 \%$ & 0,00 & 0,00 & 0,00 & 1,000 \\
\hline Electrode Error*Regime & 2 & 2,82 & $0,05 \%$ & 2,82 & 1,41 & 0,07 & 0,933 \\
\hline 3-Way Interactions & 2 & 0,00 & $0,00 \%$ & 0,00 & 0,00 & 0,00 & 1,000 \\
\hline Alloy*Electrode Error*Regime & 2 & 0,00 & $0,00 \%$ & 0,00 & 0,00 & 0,00 & 1,000 \\
\hline Error & 22 & 449,81 & $8,40 \%$ & 449,81 & 20,45 & & \\
\hline Total & 35 & 5356,85 & $100,00 \%$ & & & & \\
\hline R-sq & R-sq(adj) & R-sq(pred) & & & &
\end{tabular}
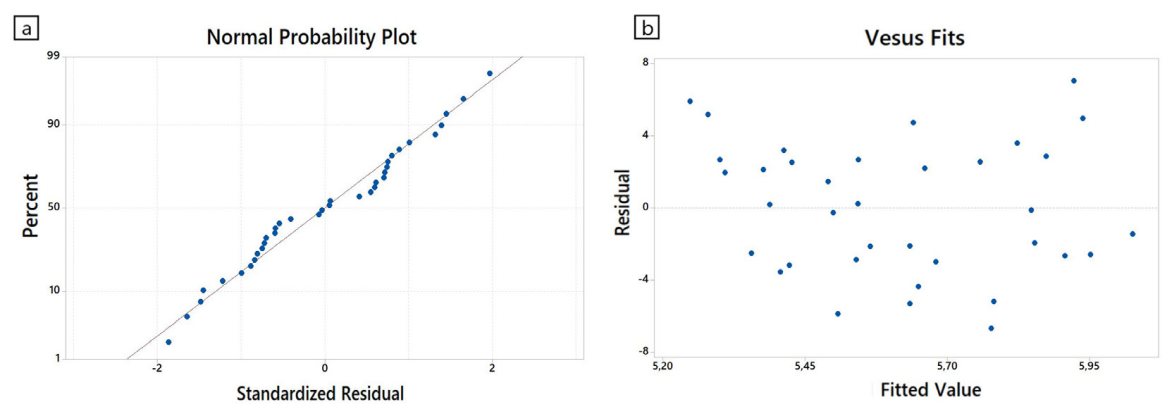

Figure 6. Residual plots analysis for ANOVA treatment validation.
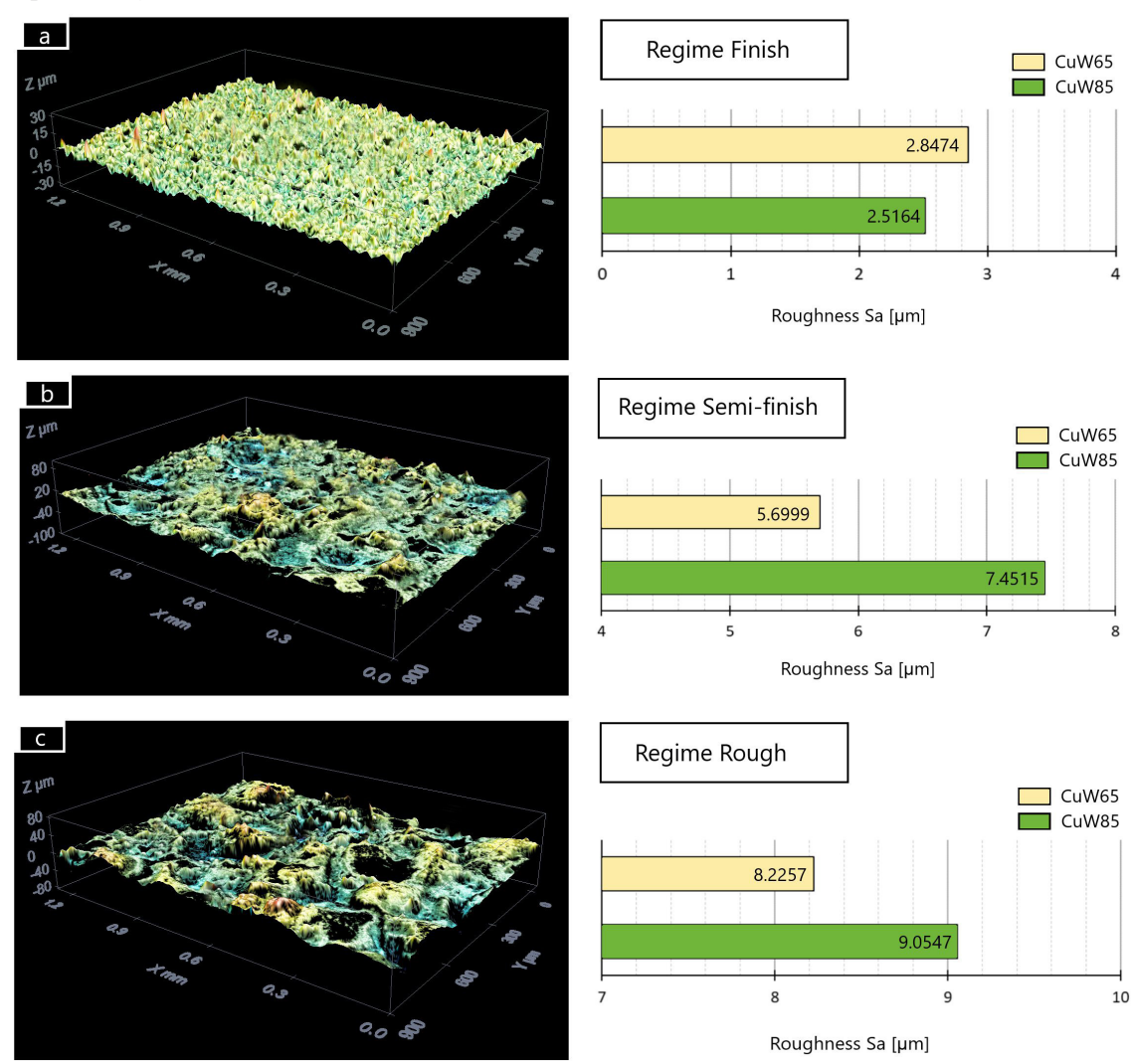

Figure 7.3D topography and WC-Co surface roughness Sa results for ED-Machining under (a) finish $\left(i_{e}=4 A, t_{e}=13 \mu s\right)$, (b) semi-finish $\left(i_{e}=11 \mathrm{~A}, \mathrm{t}_{\mathrm{e}}=56 \mu \mathrm{s}\right)$ and $(\mathrm{c})$ rough $\left(\mathrm{i}_{\mathrm{e}}=37 \mathrm{~A}, \mathrm{t}_{\mathrm{e}}=180 \mu \mathrm{s}\right)$ regimes using the two CuW electrodes grades $(\mathrm{CuW} 65 \%$ and $\mathrm{CuW} 85 \%)$. 
Table 5. ANOVA table for ED-Machining effects on WC-Co workpiece surface roughness.

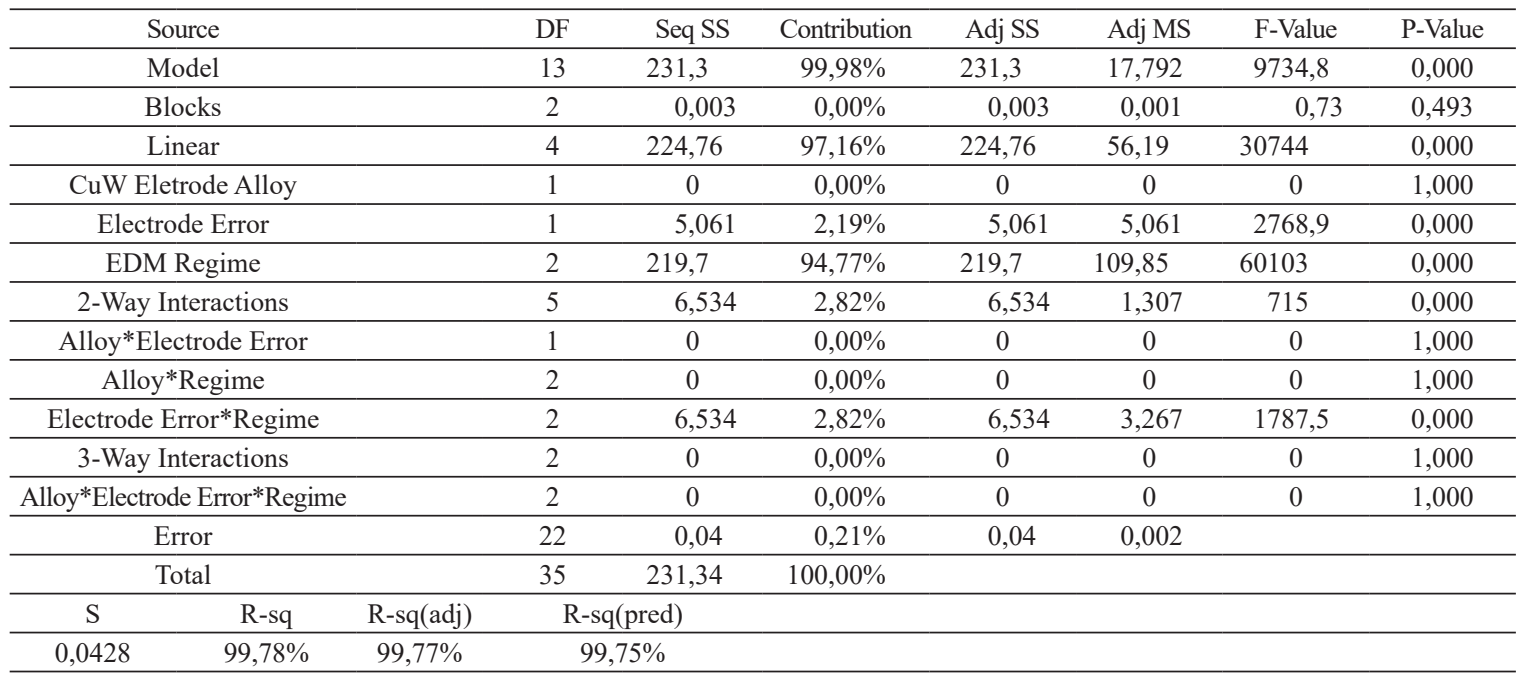
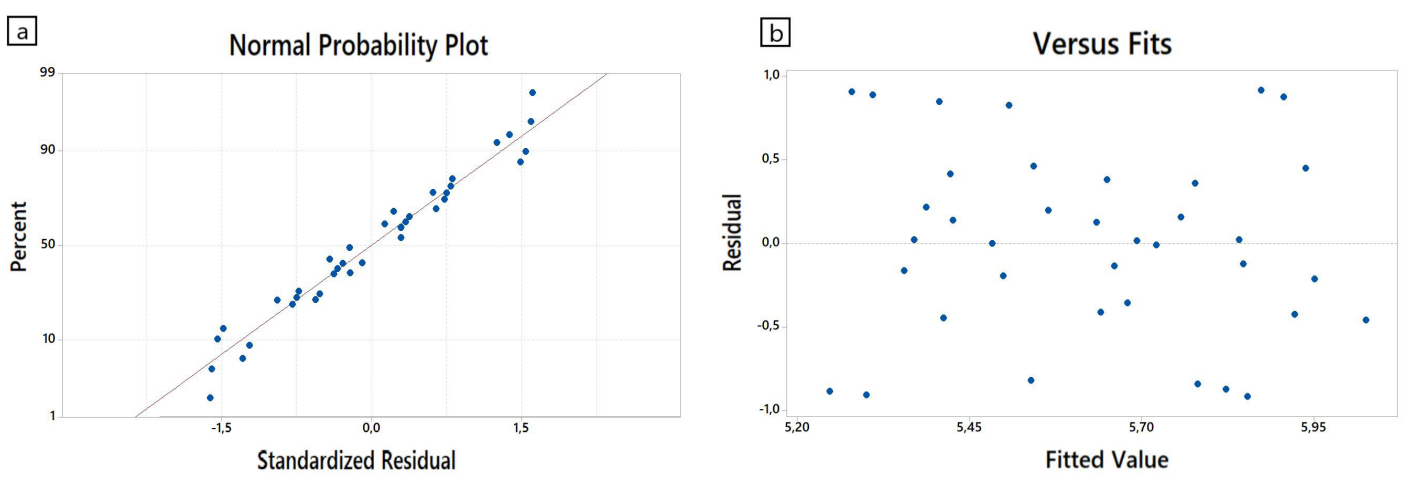

Figure 8. Residual plots analysis for ANOVA treatment validation.

$\left(i_{e}=37 \mathrm{~A}, \mathrm{t}_{\mathrm{e}}=180 \mu \mathrm{s}\right)$, semi-finish $\left(\mathrm{i}_{\mathrm{e}}=11 \mathrm{~A}, \mathrm{t}_{\mathrm{e}}=56 \mu \mathrm{s}\right)$ and finish regimes $\left(i_{e}=4 A, t_{e}=13 \mu \mathrm{s}\right)$, using the two $\mathrm{CuW}$ electrodes grades (CuW65\% and $\mathrm{CuW} 85 \%$ ). An area of $1.200 \mathrm{~mm}^{2}$ was scanned and the 3D surface roughness Sa (average height of selected area) was measured. Regardless the $\mathrm{CuW}$ electrode grade is possible to observe that from rough to finish regimes the workpiece surface roughness is improved as the discharge energy $\left(\mathrm{W}_{\mathrm{e}} \approx \mathrm{u}_{\mathrm{e}} \cdot \mathrm{i}_{\mathrm{e}} \cdot \mathrm{t}_{\mathrm{e}}[\mathrm{mJ}]\right)$ decreases. In this work for roughing, semi-finish and finish ED-machining regimes the WC-Co workpiece surface roughness Sa of about 9.0-8.2 $\mu \mathrm{m}, 7.4-5.7 \mu \mathrm{m}$ and 2.5-2.8 $\mu \mathrm{m}$, respectively for electrodes $\mathrm{CuW} 85$ and $\mathrm{CuW} 65$, was obtained. Is possible to verify that for both $\mathrm{CuW}$ electrode grades the roughness Sa becomes higher as the discharge current $i_{e}$ increases, which is due to the formation of larger and deeper craters on the workpiece surface.

An analysis of variance (ANOVA) is given in Table 5 for WC-Co workpiece surface roughness. The ANOVA results show an error of $0,2 \%$, which means that the relational analysis results have an accuracy of $99.7 \%$ in significant level of $95 \%$. The output ANOVA results clearly show that ED-Machining regime (94.7\%) plays a major role in determining the WC-Co workpiece surface roughness. The two $\mathrm{CuW}$ electrode grades (CuW65 and CuW85) do not have significant influences on surfaced roughness.
In order to validate the ANOVA results a standardized residual analysis was carried out to verify that there is no distribution of occurrences with respect to the reference line in Figure 8a. A second test, shown in Figure 8b, was done to check if there is a trend among the factors. It is observed that the greater the dispersion the lower the trend on the variables. So, it means that the ANOVA treatment can be considered as valid.

\section{Conclusions}

This work investigated the electrical discharge machining (EDM) of cemented carbide (WC-Co) with 10\% Co using two grades of coper-tungsten (CuW) electrodes with $65 \%$ and $85 \%$ of tungsten. The output variables analyzed were the WC-Co workpiece geometrical characteristics 3D surface roughness and round cavities circularity measures under rough, semifinish and finish ED-machining. From the results the following conclusions can be presented: (i) $\mathrm{CuW}$ electrode grades (CuW65\% and $\mathrm{CuW} 85 \%$ ) has slightly influences on WC-Co workpiece roughness, (ii) ED-Machining regimes plays a major role in determining the WC-Co workpiece circularity and surface roughness measures, (iii) from finish to rough regimes, independently of $\mathrm{CuW}$ electrode grade, the circularity variation increases substantially, (iv) existence of circularity deviations within the same regime was observed, and such deviations are more prominent for the roughing 
and semi-finishing regimes (v) regardless the $\mathrm{CuW}$ electrode grade is observed that from rough to finish regimes the workpiece surface roughness is improved as the discharge energy decreases and (vi) increased surface roughness contributes to increase circularity error.

\section{Acknowledgements}

The authors are thankful to Prof. Gabriel Costa Sousa, M.Eng. (Mechanical department, Instituto Federal de Santa Catarina - IFSC, Câmpus Florianópolis / Brazil) for his cooperation.

\section{References}

1. Marafona J, Wykes C. New method of optimising material removal rate using EDM with copper-tungsten electrodes. Int $\mathrm{J}$ Mach Tools Manuf. 2000;40:153-64. http://dx.doi.org/10.1016/ S0890-6955(99)00062-0.

2. Torres A, Puertas I, Luis CJ. EDM machinability and surface roughness analysis of INCONEL 600 using graphite electrodes. Int J Adv Manuf Technol. 2016;84:2671-88. http://dx.doi. org/10.1007/s00170-015-7880-x.

3. Czelusniak T, Higa CF, Torres RD, Laurindo CAH, Paiva JMF Jr, Lohrengel A et al. Materials used for sinking EDM electrodes: a review. J Braz Soc Mech Sci Eng. 2019;41:14. http://dx.doi.org/10.1007/s40430-018-1520-y.

4. Klocke F, Zeis M, Klink A, Veselovac D. Technological and economical comparison of roughing strategies via milling, sinking-EDM, wire-EDM and ECM for titanium- and nickelbased blisks. CIRO J Manuf Sci Technol. 2013;6:198-203. http://dx.doi.org/10.1006/jxra.1996.0005.

5. Duszová A, Halgaš R, Bl'anda M, Hvizdoš P, Lofaj F, Dusza J, et al. Nanoindentation of WC-Co hardmetals. J Eur Ceram Soc. 2013;33:2227-32. http://dx.doi.org/10.1016/j. jeurceramsoc.2012.12.018

6. Amorim FL, Weingaertner WL, Bassani IA. Aspects on the optimization of die-sinking EDM of tungsten carbide-cobalt. J Braz Soc Mech Sci Eng. 2010;32:496-502. http://dx.doi. org/10.1590/S1678-58782010000500009.

7. Qu J, Riester LL, Shih AJ, Scattergood RO, Lara-Curzio E, Watkins TR. Nanoindentation characterization of surface layers of electrical discharge machined WC-Co. Mater Sci Eng A. 2003;344:125-31. http://dx.doi.org/10.1016/S0921-5093(02)00395-7.

8. Carlini G, Xavier FA, Weingaertner WL, Di Maiochi H, Fodi E. Análise de parâmetros na remoção de metal duro utilizando WEDM. In: X Congresso Nacional de Engenharia Mecânica; 2018 May 20-24; Salvador. Anais. Rio de Janeiro: ABCM; 2018. https://doi.org/10.26678/ABCM.CONEM2018.CON18-1266.

9. Mukund R, Patel MAB, Eubank PT. Theoretical models of the electrical discharge machining process II: the anode erosion model. J Appl Phys. 1989;66:4104-11.

10. Senthilkumar TS, Muralikannan R. Enhancing the geometric tolerance of aluminium hybrid metal matrix composite using
EDM process. J Braz Soc Mech Sci Eng. 2019;41:1-15. http:// dx.doi.org/10.1007/s40430-018-1553-2.

11. Kumar S, Dhanabalan S. Influence on machinability and form tolerance of Inconel 718 in Edm using different diameter multi hole $\mathrm{Cu}$ electrodes. SN Appl Sci. 2019;1:1-17. http://dx.doi. org/10.1007/s42452-019-0403-x.

12. Selvarajan L, Narayanan CS, Jeyapaul R. Optimization of EDM Parameters on Machining Si 3N4-TiN composite for improving circularity, cylindricity, and perpendicularity. Mater Manuf Process. 2016;31:405-12. http://dx.doi.org/10.1080/10 426914.2015.1058947.

13. Takashimizu Y, Iiyoshi M. New parameter of roundness R: Circularity corrected by aspect ratio. Prog Earth Planet Sci. 2016;3:1-16. http://dx.doi.org/10.1186/s40645-015-0078-x.

14. Adamczak S, Janecki D, Stępień K. The comparison of cylindricity profiles using normalized cross correlation function. Meas Sci Rev. 2006;6:18-21.

15. Dhanabalan S, Sivakumar K, Narayanan CS. Analysis of form tolerances in electrical discharge machining process for inconel 718 and 625. Mater Manuf Process. 2014;29:253-9. http:// dx.doi.org/10.1080/10426914.2013.852213.

16. Popli D, Gupta M. Investigation of the circularity and conicity of super alloy during rotary ultrasonic machining. Iran J Sci Technol Trans Mech Eng. 2018;2:1-21 http://dx.doi.org/10.1007/ s40997-018-0197-2.

17. Tiwary P, Pradhan B, Bhattacharyya B. Investigation on the effect of dielectrics during micro-electro-discharge machining of Ti-6Al-4V. Int J Adv Manuf Technol. 2018;95:861-74. http:// dx.doi.org/10.1007/s00170-017-1231-z.

18. D'Urso G, Merla C. Workpiece and electrode influence on micro-EDM drilling performance. Precis Eng. 2014;38:903-14. http://dx.doi.org/10.1016/j.precisioneng.2014.05.007.

19. Murray JW, Sun J, Patil DV, Wood TA, Clare AT. Physical and electrical characteristics of EDM debris. J Mater Process Technol. 2016;229:54-60. http://dx.doi.org/10.1016/j. jmatprotec.2015.09.019.

20. Muttamara A, Borwornkiatkaew W, Pronpijit A, Nuanchom S. Effect of Graphite Electrode to Surface's Characteristic of EDM. MATEC Web Conf. 2016;70(01002):1-4. https://doi. org/10.1051/matecconf/20167001002.

21. Shabgard MR, Ivanov A, Rees A. Influence of EDM machining on surface integrity of WC-Co. Woodhead Publishing Limited; 2006.

22. Kunieda M, Lauwers B, Rajurkar KP, Schumacher BM. Advancing EDM through Fundamental Insight into the Process. CIRP Ann - Manuf Technol. 2005;54:64-87. https://doi.org/10.1016/ S0007-8506(07)60020-1.

23. Bassoli E, Denti L, Gatto A, Iuliano L. Influence of electrode size and geometry in electro-discharge drilling of Inconel 718. Int J Adv Manuf Technol. 2016;86(5-8):2329-37.

24. Lee SH, Li XP. Study of the effect of machining parameters on the machining characteristics in electrical discharge machining of tungsten carbide. J Mater Process Technol. 2001;115(3):344-58.

25. Rizvi SAH, Agarwal S. An Investigation on surface integrity in EDM Process with a Copper Tungsten Electrode. Procedia CIRP. 2016;42:612-617. 